\title{
MCM-41-Accelerated PWA Catalysis of Friedel-Crafts Reaction of Indoles and Isatins
}

\author{
Liuzhuang Xing, ${ }^{1}$ YongHai Hui $\mathbb{D}^{1},{ }^{1}$ Jinghui Yang, ${ }^{1}$ Xuejian Xing, ${ }^{1}$ Yadong Hou, \\ Yang Wu, ${ }^{1}$ Kui Fan, ${ }^{1}$ and Wei Wang (iD ${ }^{2}$
}

${ }^{1}$ Key Laboratory of Oil \& Gas Fine Chemicals, Ministry of Education \& Xinjiang Uyghur Autonomous Region, College of Chemistry and Chemical Engineering, Xinjiang University, Urumqi 830046, China

${ }^{2}$ Department of Chemistry and Centre for Pharmacy, University of Bergen, 5020 Bergen, Norway

Correspondence should be addressed to YongHai Hui; hyhai97@126.com and Wei Wang; wei.wang@uib.no

Received 22 July 2017; Accepted 1 November 2017; Published 18 January 2018

Academic Editor: Pasquale Longo

Copyright (c) 2018 Liuzhuang Xing et al. This is an open access article distributed under the Creative Commons Attribution License, which permits unrestricted use, distribution, and reproduction in any medium, provided the original work is properly cited.

Ordered mesoporous siliceous material has been identified as one of the key elements of the catalysis concept. Here we report an efficient Friedel-Crafts reaction of indoles with isatins catalyzed by PWA/MCM-41, which got the di(indolyl)indolin-2-ones derivatives with high yield. Moreover, the catalysts were characterized by XRD and SEM/EDS, the EDS spectrum indicated that the catalyst used in this reaction also contains tungsten, and the proposed mechanism for the synthesis of 3,3-di(indolyl)indolin-2-ones was also discussed. Finally, the catalyst can be reused repeatedly for several times without obvious loss of activity.

\section{Introduction}

Friedel-Crafts reaction is a fundamental transformation for $\mathrm{C}-\mathrm{C}$ bonds formation in organic synthesis [1]. Among the Friedel-Crafts reaction substrate of aromatic compounds, indoles and indole derivatives have received more and more attention [2] because of their privileged structure and quite pervasiveness in nature [3] as well as their excellent biological activities [4]. Isatin is one of the most important derivatives of indole with significant bioactive scaffold, containing double adjacent carbonyls with an indole unit and a $\gamma$-lactam moiety, which endows isatin with an amount of interesting synthetic applications [5].

The carbonyl group in 3-position of isatins readily makes isatins undergo electrophilic condensation reactions with indoles to produce 3,3-di(indolyl)indolin-2-ones, which also show excellent bioactivities [6-8]. Some literature sources revealed that the synthesis of 3,3-diaryloxindole skeleton can be achieved by coupling of indoles and isatins with acid $[9,10], \mathrm{I}_{2}[11]$, metal salts [12], ionic liquids [13], CAN [14], $\beta$ CD [15], Amberlyst-15 [16], and nanomaterials [17]. Despite these important contributions, developing and searching for a highly effective catalytic system is still challenging.
In the last few years, ordered mesoporous siliceous material supporting catalysts have been paid much attention because of their high surface areas, large pores, and ordered arrangement of structures [18]. Phosphotungstic acid (PWA) supported on heterogeneous materials has been widely used for Friedel-Crafts reaction $[19,20]$. As a continuation of our interest in catalyst of supported mesoporous material in the organic synthesis $[21,22]$, herein, we reported isatins as the electrophiles to react with indoles using PWA/MCM41 as catalyst at room temperature for the synthesis of 3,3di(indolyl)indolin-2-ones.

\section{Experimental}

The purity of compounds was checked by thin layer chromatography (TLC) using ethyl acetate/petroleum ether (v/v) as eluent; IR spectrum was recorded on a Bruker Equinox 55 FT-IR spectrophotometer as $\mathrm{KBr}$ discs. The ${ }^{1} \mathrm{H}$ NMR and ${ }^{13} \mathrm{C}$ NMR spectra were recorded on an INOVA $(400 \mathrm{MHz})$ FT-NMR spectrometer in $\mathrm{CDCl}_{3}$ using TMS as an internal standard. The prepared catalysts were characterized by XRD, SEM, and EDS. 
<smiles>c1ccc2[nH]ccc2c1</smiles>

$1 \mathbf{a}$

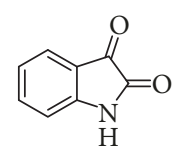

$2 \mathbf{a}$

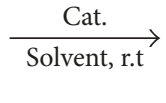

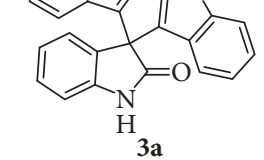

Scheme 1: The Friedel-Crafts reaction of indole with isatin.

Indoles $(0.20 \mathrm{mmol})$, isatins $(0.10 \mathrm{mmol})$, and $60 \mathrm{wt} \%$ PWA/MCM-41 catalyst $(0.0050 \mathrm{~g})$ were stirred in THF $(0.3 \mathrm{~mL})$ at room temperature for $2.5 \mathrm{~h}$ and monitored by TLC. The product were purified by column chromatography on silica gel using petroleum ether/ethyl acetate $(20: 1,10: 1$, $5: 1,2: 1,1: 1)$ as the eluent. All compounds (3a-3o) were characterized by ${ }^{1} \mathrm{H}$ and ${ }^{13} \mathrm{C}$ NMR $(400 \mathrm{MHz})$ spectral analysis. The catalyst was separated from the reaction mixture by centrifugalization, dried at $473 \mathrm{~K}$ for $4 \mathrm{~h}$ after washing with ethanol, then continued to be reused for the next reaction.

\section{Results and Discussion}

Initially, as a continuation of our work on the applications of mesoporous siliceous material catalysts for organic reaction, to optimize the reaction condition of the Friedel-Crafts reaction of indoles with isatins, we utilized isatin $(0.10 \mathrm{mmol})$ and indole $(0.20 \mathrm{mmol})$ as model substrates (Scheme 1$)$, and the results are shown in Table 1 . MCM-41 or PMoA as catalysts led to lower yields than PWA as catalyst (Table 1, entries (1)-(3)). To our delight, the yield was significantly improved with PWA/MCM-41 catalyzing the model reaction and the $60 \mathrm{wt} \%$ PWA/MCM-41 being the optimized catalyst that contrasted with (40-80) wt $\%$ and obtained up to $86 \%$ yield (Table 1, entries (4)-(8)). With the ratio of PWA/MCM-41 exceeding $60 \mathrm{wt} \%$, the yields of the 3,3-di(indolyl)indolin-2one decreased, because the MCM-41 pores might be blocked by the excessive amounts of PWA. Comparative experiments indicated that the pores indeed facilitated the Friedel-Crafts reaction [21].

The optimal catalyst was established, and further screening of the reaction conditions was focused on solvents, catalyst quantity, solvent quantity, and reaction time. The results revealed that the use of THF as a reaction medium was superior to other solvents (Table 1, entry (6) versus entries (9)-(15)). And with the amount of catalyst reduced from $0.0050 \mathrm{~g}$ to $0.0030 \mathrm{~g}$, the yield of the reaction was significantly decreased (Table 1, entries (16) and (17)). However, the amount of solvent obviously influenced the formation of the 3,3-di(indolyl)indolin-2-one and the best outcome was obtained with $0.3 \mathrm{~mL}$ THF at $0.1 \mathrm{mmol}$ scale of isatin (Table 1 , entry (18)). To our delight, the reaction time was slightly decreased to $2.5 \mathrm{~h}$ and could also successfully deliver the desired product in excellent yield up to $99 \%$ (Table 1 , entry (19)). Therefore, $(0.005 \mathrm{~g}) 60 \mathrm{wt} \%$ PWA/MCM-41 catalyzed $(0.10 \mathrm{mmol})$ isatins with $(0.20 \mathrm{mmol})$ indoles with $(0.3 \mathrm{~mL})$ THF at room temperature for $2.5 \mathrm{~h}$, which proved to be a robust method to build up the 3,3-di(indolyl)indolin-2-ones scaffold.
TABLE 1: Optimization of the reaction conditions ${ }^{\mathrm{a}}$.

\begin{tabular}{|c|c|c|c|c|}
\hline Entry & Catalyst & Solvent & $\begin{array}{l}\text { Time } \\
\text { (h) }\end{array}$ & $\begin{array}{l}\text { Yield } \\
(\%)^{\mathrm{b}}\end{array}$ \\
\hline (1) & MCM-41 & THF & 3 & 31 \\
\hline (2) & $\mathrm{PMoA}$ & THF & 3 & 39 \\
\hline (3) & PWA & THF & 3 & 46 \\
\hline (4) & $40 \mathrm{wt} \%$ PWA/MCM-41 & THF & 3 & 53 \\
\hline (5) & $50 \mathrm{wt} \%$ PWA/MCM-41 & THF & 3 & 60 \\
\hline (6) & $60 \mathrm{wt} \%$ PWA/MCM-41 & THF & 3 & 86 \\
\hline (7) & 70 wt $\%$ PWA/MCM-41 & THF & 3 & 70 \\
\hline (8) & 80 wt $\%$ PWA/MCM-41 & THF & 3 & 68 \\
\hline (9) & $60 \mathrm{wt} \%$ PWA/MCM-41 & $\mathrm{EtOH}$ & 3 & 73 \\
\hline (10) & $60 \mathrm{wt} \%$ PWA/MCM-41 & $\mathrm{Et}_{2} \mathrm{O}$ & 3 & 54 \\
\hline (11) & $60 \mathrm{wt} \%$ PWA/MCM-41 & AcOEt & 3 & 35 \\
\hline (12) & $60 \mathrm{wt} \%$ PWA/MCM-41 & acetone & 3 & 47 \\
\hline (13) & $60 \mathrm{wt} \%$ PWA/MCM-41 & toluene & 3 & 47 \\
\hline (14) & 60 wt $\%$ PWA/MCM-41 & $\mathrm{CH}_{3} \mathrm{CN}$ & 3 & 34 \\
\hline (15) & $60 \mathrm{wt} \%$ PWA/MCM-41 & $\mathrm{CH}_{2} \mathrm{Cl}_{2}$ & 3 & 24 \\
\hline$(16)^{c}$ & $60 \mathrm{wt} \%$ PWA/MCM-41 & THF & 3 & 83 \\
\hline$(17)^{\mathrm{d}}$ & 60 wt $\%$ PWA/MCM-41 & THF & 3 & 43 \\
\hline$(18)^{\mathrm{e}}$ & 60 wt $\%$ PWA/MCM-41 & THF & 3 & 99 \\
\hline$(19)^{\mathrm{e}}$ & 60 wt $\%$ PWA/MCM-41 & THF & 2.5 & 99 \\
\hline
\end{tabular}

${ }^{a}$ Reaction conditions (unless noted otherwise): $0.20 \mathrm{mmol}$ of indole, $0.10 \mathrm{mmol}$ of isatin, $0.0050 \mathrm{~g}$ of catalyst in $0.2 \mathrm{~mL}$ of solvent at room temperature for $3 \mathrm{~h} .{ }^{\mathrm{b}}$ Isolated yield. ${ }^{\mathrm{c}}$ Use $0.0040 \mathrm{~g}$ of $60 \mathrm{wt} \% \mathrm{PWA} / \mathrm{MCM}-14$ catalyst. ${ }^{\mathrm{d}}$ Use $0.0030 \mathrm{~g}$ of $60 \mathrm{wt} \%$ PWA/MCM-14 catalyst. ${ }^{\mathrm{e}} 0.3 \mathrm{~mL}$ THF.

General procedure for synthesis of catalysts was exhibited in supporting information (see SI 2.1 S1). The catalysts were characterized using SEM equipped with EDS and XRD. The EDS spectrum and elemental contents of some zones are shown in Figure 1. It can be seen that the optimal catalyst (B zone in Figure 1(b)) in this system contains rich tungsten (X-ray energy $1.774 \mathrm{keV}$ ) compared with the pure MCM-41 [23] (A zone in Figure 1(a)). Meanwhile, the EDS spectrum indicated that the catalyst used in this reaction also contains tungsten and the catalyst could be used repeatedly.

The bands in the X-ray diffraction patterns (Figure 2) of pure MCM-41 (a), as well as the catalyst of PWA supported on MCM-41 (b) and the used catalyst PWA/MCM-41 (c) in the range of $1^{\circ}-8^{\circ}$ (Figure $2(\mathrm{a})$ ), suggest that the hexagonal pore arrangement was kept [24]. The catalyst of $60 \mathrm{wt} \%$ PWA/MCM-41 exhibited clear diffractions at $10.2^{\circ}, 20.7^{\circ}$, $22.5^{\circ}, 29.6^{\circ}$, and $34.9^{\circ}$ compared with pure MCM-41 that was associated with PWA (Figure 2(b)) [25], suggesting that PWA was supported on MCM-41 and the catalyst of PWA remained after catalyzing this reaction.

With the optimized parameters established, the substrate scope was investigated (Scheme 2) and the results were listed in Table 2. When the phenyl ring of indoles or isatins interacts with methyl substituent, the desired products $\mathbf{3 b} \mathbf{b} \mathbf{3 d}$ and $3 \mathbf{k}$ are obtained in a moderate to good yield (Table 2, entries (2)-(4), (11)). However, product 31, the yield of 5methyl-3,3-di(indolyl) oxindole, was excellent (Table 2, entry 


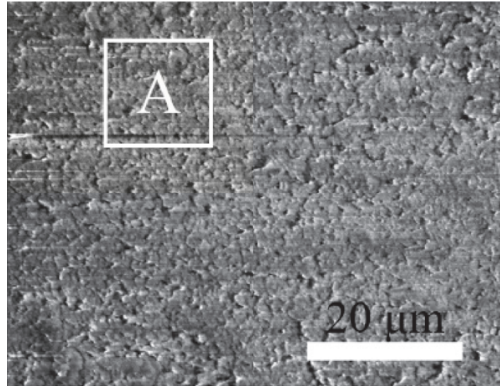

(a)

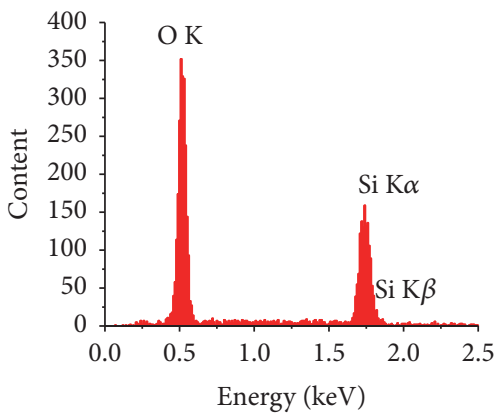

(d)

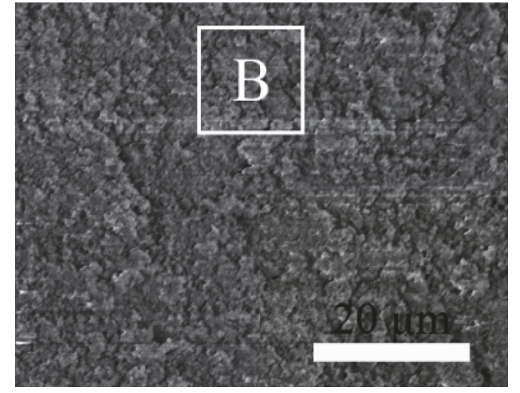

(b)

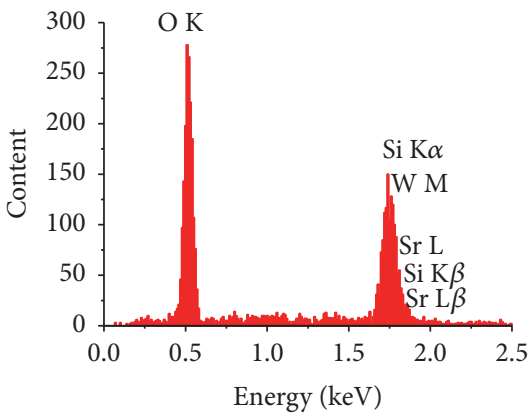

(e)

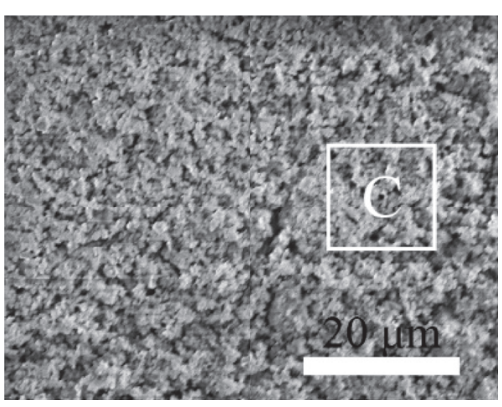

(c)

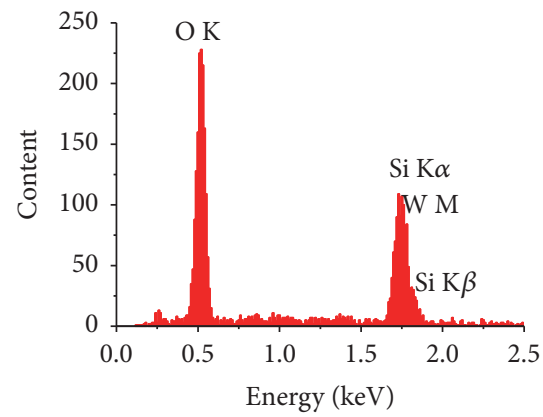

(f)

FIGURE 1: The SEM of pure MCM-41 (a), fresh catalyst $60 \mathrm{wt} \%$ PWA/MCM-41 (b), used catalyst $60 \mathrm{wt} \%$ PWA/MCM-41 (c), and EDS spectrum and elemental contents of the region $\mathrm{A}$ in (d), region $\mathrm{B}$ in (e), and region $\mathrm{C}$ in (f).
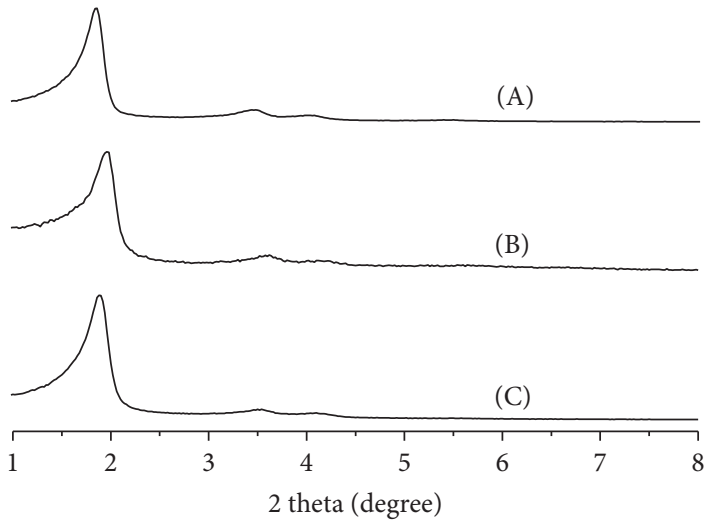

(a)
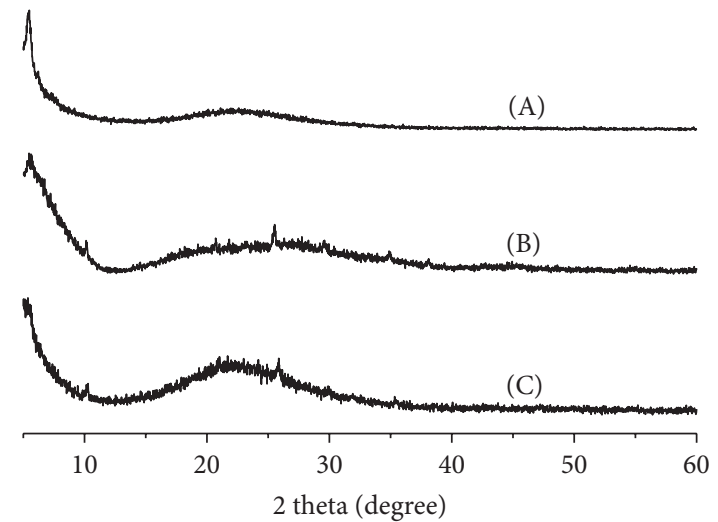

(b)

FIGURE 2: The small-angle range XRD (a) and wide-angle range XRD (b), pure MCM-41 (A), fresh catalyst 60 wt\% PWA/MCM-41 (B), and used catalyst $60 \mathrm{wt} \%$ PWA/MCM-41 (C).

(12)). Wherever $-\mathrm{F}$ and $-\mathrm{Cl}$ groups are located in indoles or isatins of aromatic rings, they all could be tolerated well and gave the desired product derivatives $\mathbf{3 e}-\mathbf{3 h}, \mathbf{3 m}$, and $\mathbf{3 o}$ in excellent yields (Table 2, entries (5)-(8), (13), and (15)). However, the benzene ring of indoles or isatins bearing sterically demanding groups, such as $-\mathrm{Br}$ and $-\mathrm{NO}_{2}$, could only give corresponding products with lower yields, respectively (Table 2, entries (9), (10), and (14)). All compounds (3a-3o) were characterized by ${ }^{1} \mathrm{H}$ and ${ }^{13} \mathrm{C}$ NMR $(400 \mathrm{MHz})$ spectral analysis (for all physical data of compounds, see SI 3 S2-S11).

On the basis of previous studies [9] and above results, a mechanism for this reaction was proposed. The first step is the activation of the 3-position carbonyl group of isatin (2) by $60 \mathrm{wt} \%$ PWA/MCM-41, which facilitates nucleophilic addition of indole (1) to form corresponding 3-hydroxy3-indolyl oxindole (5). Then, hydrogen of indolyloxindole transferred to hydroxyl group and gave the intermediate (6), followed by its dehydration to (7). Finally, another indole reacted with (7) to provide the desired product 3,3di(indolyl)indolin-2-one (3) and regenerate the catalyst for the next catalytic cycle (Scheme 3 ).

The study of reusability of catalytic is an important aspect of green chemistry. To investigate it, we used the above model reaction and optimized condition. After completion 


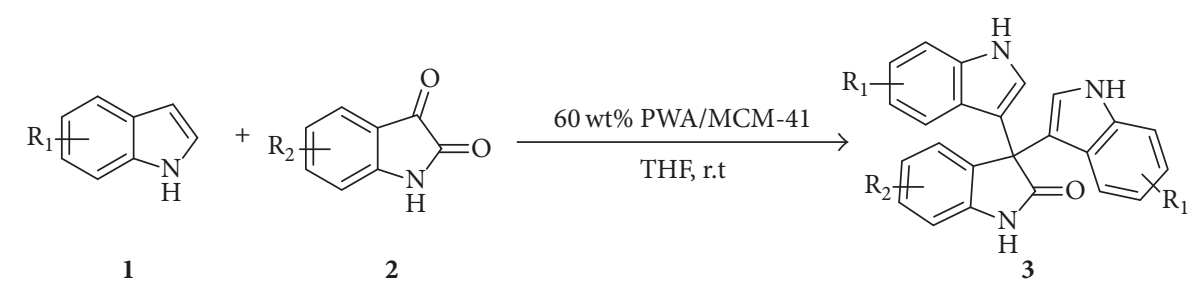

Scheme 2: The Friedel-Crafts reaction of indoles with isatins.

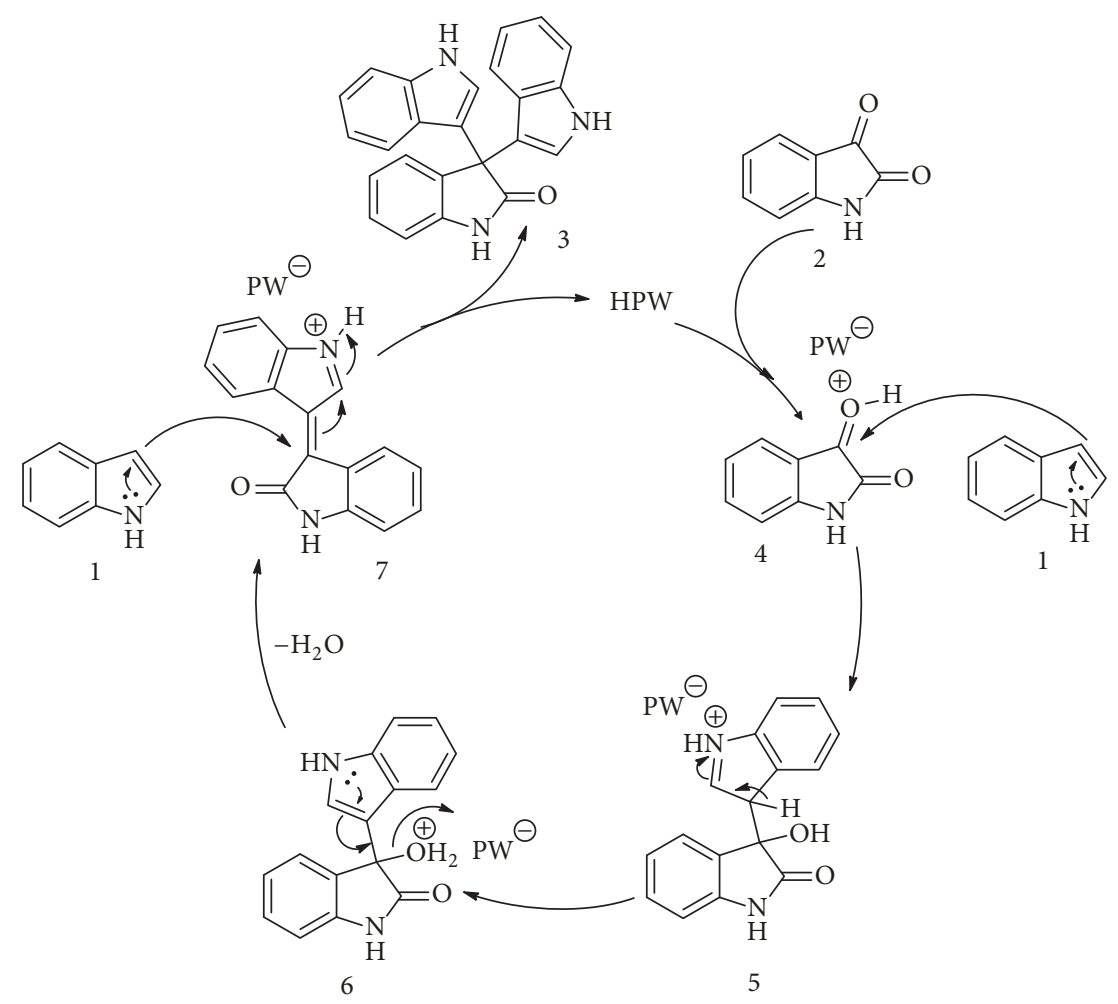

Scheme 3: Proposed catalytic mechanism.

of the reaction, the catalyst was separated from the reaction mixture by centrifugalization, then washed with ethanol, and dried at $473 \mathrm{~K}$ for $4 \mathrm{~h}$. The recovered catalyst was used for five consecutive reactions with no significant loss of activity (Figure 3) (for general cyclic procedure, see SI 2.3 S2).

\section{Conclusion}

In summary, we developed an efficient heterogeneous PWA/ MCM-41 catalyzed Friedel-Crafts reaction of isatins with indoles, delivering a series of 3,3-di(indolyl)indolin-2-ones. The catalytic reaction could be carried out under mild conditions with broad substrate scope, good efficiency, and well functional group compatibility. Furthermore, the catalyst keeps the basic hexagonal pore arrangement and the components of PWA. The recovered catalyst was reused for five consecutive reactions with no significant loss of activity. Further investigation focusing on the scope of the currently synthetic applications is being conducted in our group.

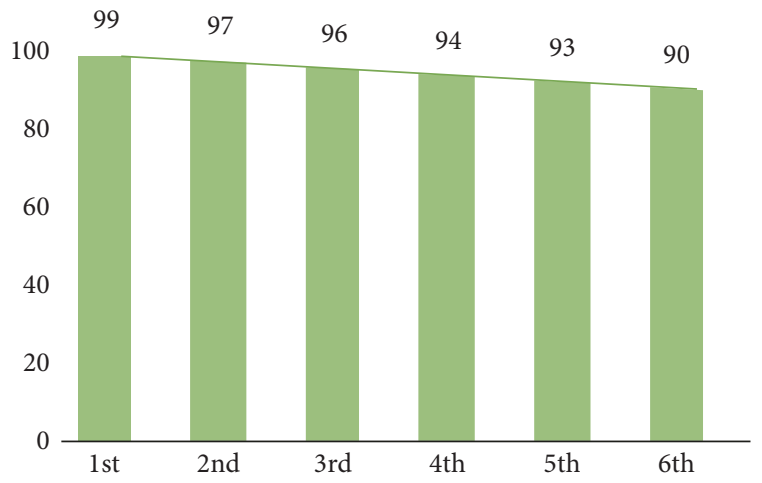

FIGURE 3: Reusability of the catalyst $60 \mathrm{wt} \%$ PWA/MCM-41.

\section{Conflicts of Interest}

All authors declare no conflicts of interest. 
TABLE 2: Substrate scope for the cyclocondensation recation ${ }^{\mathrm{a}}$.

\begin{tabular}{lcccccc}
\hline Entry & $\mathrm{R}^{1}$ & $\mathrm{R}^{2}$ & Products & $\begin{array}{c}\text { Yield } \\
(\%)^{\mathrm{b}}\end{array}$ & $\begin{array}{c}\text { Yield } \\
(\%)^{\mathrm{c}}\end{array}$ & Ref. \\
\hline$(1)$ & $\mathrm{H}$ & $\mathrm{H}$ & $\mathbf{3 a}$ & 99 & 89 & {$[10]$} \\
$(2)$ & $2-\mathrm{CH}_{3}$ & $\mathrm{H}$ & $\mathbf{3 b}$ & 70 & 91 & {$[9]$} \\
$(3)$ & $5-\mathrm{CH}_{3}$ & $\mathrm{H}$ & $\mathbf{3 c}$ & 55 & 85 & {$[14]$} \\
$(4)$ & $6-\mathrm{CH}_{3}$ & $\mathrm{H}$ & $\mathbf{3 d}$ & 80 & 86 & {$[14]$} \\
$(5)$ & $5-\mathrm{F}$ & $\mathrm{H}$ & $\mathbf{3 e}$ & 96 & 87 & {$[10]$} \\
$(6)$ & $6-\mathrm{F}$ & $\mathrm{H}$ & $\mathbf{3 f}$ & 98 & - & - \\
$(7)$ & $5-\mathrm{Cl}$ & $\mathrm{H}$ & $\mathbf{3 g}$ & 98 & 89 & {$[26]$} \\
$(8)$ & $6-\mathrm{Cl}^{2}$ & $\mathrm{H}$ & $\mathbf{3 h}$ & 98 & 91 & {$[26]$} \\
$(9)$ & $5-\mathrm{NO}_{2}$ & $\mathrm{H}$ & $\mathbf{3 i}$ & 72 & 84 & {$[14]$} \\
$(10)$ & $6-\mathrm{NO}_{2}$ & $\mathrm{H}$ & $\mathbf{3 j}$ & 64 & - & - \\
$(11)$ & $\mathrm{H}$ & $1-\mathrm{CH}_{3}$ & $\mathbf{3 k}$ & 76 & 91 & {$[10]$} \\
$(12)$ & $\mathrm{H}$ & $5-\mathrm{CH} \mathrm{H}_{3}$ & $\mathbf{3 1}$ & 98 & 90 & {$[9]$} \\
$(13)$ & $\mathrm{H}$ & $5-\mathrm{Cl}$ & $\mathbf{3 m}$ & 99 & 86 & {$[10]$} \\
$(14)$ & $\mathrm{H}$ & $4-\mathrm{Br}$ & $\mathbf{3 n}$ & 60 & 90 & {$[14]$} \\
$(15)$ & $\mathrm{H}$ & $7-\mathrm{F}$ & $\mathbf{3 0}$ & 99 & - & - \\
\hline
\end{tabular}

${ }^{\mathrm{a}}$ Reaction conditions (unless noted otherwise): indoles $(1,0.20 \mathrm{mmol}$ ), isatins $(2,0.10 \mathrm{mmol})$, and $0.0050 \mathrm{~g} 60 \mathrm{wt} \% \mathrm{PWA} / \mathrm{MCM}-41$ as catalyst in $0.3 \mathrm{~mL}$ THF at room temperature for $2.5 \mathrm{~h}$. ${ }^{\mathrm{b}}$ Isolated yield. ${ }^{\mathrm{c}}$ Yield of reference.

\section{Acknowledgments}

The authors acknowledge the National Natural Science Foundation of China (nos. 21362036 and 21162026) and the Thousand Talents Plan for financial support, Xinjiang University Analytical \& Testing Center for instrumental analyses, and Adamas-beta Chemical Co. for all chemical reagents.

\section{Supplementary Materials}

Supplementary data and general procedure for synthesis of catalyst PWA/MCM-41 associated with this article can be found in the attached file. These data include NMR $\left({ }^{1} \mathrm{H}\right.$ and $\left.{ }^{13} \mathrm{C}\right)$, IR, melting point, and yield of the synthesized compounds (3a-3o). (Supplementary Materials)

\section{References}

[1] G. Sartori and R. Maggi, "Use of solid catalysts in Friedel-Crafts acylation reactions," Chemical Reviews, vol. 111, no. 20, pp. 181214, 2011.

[2] X. Liang, S. Z. Jiang, K. Wei, and Y. R. Yang, "Enantioselective total synthesis of (-)-Alstoscholarisine A," Journal of the American Chemical Society, vol. 138, no. 8, pp. 2560-2562, 2016.

[3] G. R. Pettit, J. D. Searcy, R. Tan et al., "Antineoplastic Agents. 585. Isolation of Bridelia ferruginea Anticancer Podophyllotoxins and Synthesis of 4-Aza-podophyllotoxin Structural Modifications," Journal of Natural Products, vol. 79, no. 3, pp. 507-518, 2016.

[4] H. Gurer-Orhan, C. Karaaslan, S. Ozcan et al., "Novel indolebased melatonin analogues: evaluation of antioxidant activity and protective effect against amyloid $\beta$-induced damage," Bioorganic \& Medicinal Chemistry, vol. 24, no. 8, pp. 1658-1664, 2016.
[5] M. S. Shmidt, I. A. Perillo, A. Camelli, M. A. Fernández, and M. M. Blanco, "Polyfunctional 4-quinolinones. Synthesis of 2substituted 3-hydroxy-4-oxo-1,4-dihydroquinolines," Tetrahedron Letters, vol. 57, no. 9, pp. 1022-1026, 2016.

[6] D. Sriram, P. Yogeeswari, N. S. Myneedu, and V. Saraswat, "Abacavir prodrugs: microwave-assisted synthesis and their evaluation of anti-HIV activities," Bioorganic and Medicinal Chemistry Letters, vol. 16, no. 8, pp. 2127-2129, 2006.

[7] T. Jiang, K. L. Kuhen, K. Wolff et al., "Design, synthesis and biological evaluations of novel oxindoles as HIV-1 nonnucleoside reverse transcriptase inhibitors. Part I," Bioorganic \& Medicinal Chemistry Letters, vol. 16, no. 8, pp. 2105-2108, 2006.

[8] A. Kamal, Y. V. V. Srikanth, M. N. A. Khan, T. B. Shaik, and M. Ashraf, "Synthesis of 3,3-diindolyl oxyindoles efficiently catalysed by $\mathrm{FeCl}_{3}$ and their in vitro evaluation for anticancer activity," Bioorganic \& Medicinal Chemistry Letters, vol. 20, no. 17, pp. 5229-5231, 2010.

[9] J. Azizian, A. A. Mohammadi, N. Karimi, M. R. Mohammadizadeh, and A. R. Karimi, "Silica sulfuric acid a novel and heterogeneous catalyst for the synthesis of some new oxindole derivatives," Catalysis Communications, vol. 7, no. 10, pp. 752-755, 2006.

[10] G. Brahmachari and B. Banerjee, "Facile and one-pot access of 3,3-bis(indol-3-yl)indolin-2-ones and 2,2-bis(indol-3-yl)acenaphthylen- $1(2 \mathrm{H})$-one derivatives via an eco- friendly pseudomulticomponent reaction at room temperature using sulfamic acid as an organo-catalyst," ACS Sustainable Chemistry \& Engineering, vol. 2, no. 12, pp. 2802-2812, 2014.

[11] P. Paira, A. Hazra, S. Kumar et al., "Efficient synthesis of 3,3-diheteroaromatic oxindole analogues and their in vitro evaluation for spermicidal potential," Bioorganic \& Medicinal Chemistry Letters, vol. 19, no. 16, pp. 4786-4789, 2009.

[12] C. Praveen, A. Ayyanar, and P. T. Perumal, "Gold(III) chloride catalyzed regioselective synthesis of pyrano[3,4-b]indol-1(9H)ones and evaluation of anticancer potential towards human cervix adenocarcinoma," Bioorganic \& Medicinal Chemistry Letters, vol. 21, no. 14, pp. 4170-4173, 2011.

[13] K. Rad-Moghadam, M. Sharifi-Kiasaraie, and H. Taheri-Amlashi, "Synthesis of symmetrical and unsymmetrical 3,3-di(indolyl)indolin-2-ones under controlled catalysis of ionic liquids," Tetrahedron, vol. 66, no. 13, pp. 2316-2321, 2010.

[14] S. Y. Wang and S. J. Ji, "Facile synthesis of 3,3-di(heteroaryl)indolin-2-one derivatives catalyzed by ceric ammonium nitrate (CAN) under ultrasound irradiation," Tetrahedron, vol. 62, no. 7, pp. 1527-1535, 2006.

[15] Y. A. Tayade, D. R. Patil, Y. B. Wagh, A. D. Jangle, and D. S. Dalal, "An efficient synthesis of 3-indolyl-3-hydroxy oxindoles and 3,3-di(indolyl)indolin-2-ones catalyzed by sulfonated $\beta-\mathrm{CD}$ as a supramolecular catalyst in water," Tetrahedron Letters, vol. 56, no. 5, pp. 666-673, 2015.

[16] Y. Sarrafi, K. Alimohammadi, M. Sadatshahabi, and N. Norozipoor, "An improved catalytic method for the synthesis of 3,3di(indolyl)oxindoles using Amberlyst 15 as a heterogeneous and reusable catalyst in water," Monatshefte für Chemie, vol. 143, no. 11, pp. 1519-1522, 2012.

[17] S. Z. Sayyed-Alangi and Z. Hossaini, "ZnO nanorods as an efficient catalyst for the green synthesis of indole derivatives using isatoic anhydride," Chemistry of Heterocyclic Compounds, vol. 51, no. 6, pp. 541-544, 2015.

[18] K. Sugino, N. Oya, N. Yoshie, and M. Ogura, "A simple modification creates a great difference: new solid-base catalyst using 
methylated N-substituted SBA-15," Journal of the American Chemical Society, vol. 133, no. 50, pp. 20030-20032, 2011.

[19] Suryani, C. M. Chang, Y. L. Liu, and Y. M. Lee, "Polybenzimidazole membranes modified with polyelectrolyte-functionalized multiwalled carbon nanotubes for proton exchange membrane fuel cells," Journal of Materials Chemistry, vol. 21, no. 20, pp. 7480-7486, 2011.

[20] X. Li, G. Qin, Y. Wang, and W. Wei, "Keggin-type phosphotungstic acid supported on mesoporous $\mathrm{SiO}_{2}-\mathrm{Al}_{2} \mathrm{O}_{3}$ aerogel like beads and their application in the isopropylation of naphthalene," Journal of Sol-Gel Science and Technology, vol. 72, no. 2, pp. 405-414, 2014.

[21] K. Fan, Y. H. Hui, X. H. Hu, W. Shi, H. X. Pang, and Z. F. Xie, "PMoA/MCM-41 catalyzed aza-Michael reaction: special effects of mesoporous nanoreactor on chemical equilibrium and reaction rate through surface energy transformation," New Journal of Chemistry, vol. 39, no. 8, pp. 5916-5919, 2015.

[22] H. X. Pang, Y. H. Hui, K. Fan et al., "A catalysis study of mesoporous MCM-41 supported Schiff base and $\mathrm{CuSO}_{4} \cdot 5 \mathrm{H}_{2} \mathrm{O}$ in a highly regioselective synthesis of 4 -thiazolidinone derivatives from cyclocondensation of mercaptoacetic acid," Chinese Chemical Letters, vol. 27, no. 3, pp. 335-339, 2016.

[23] D. E. Newbury and N. W. M. Ritchie, "Performing elemental microanalysis with high accuracy and high precision by scanning electron microscopy/silicon drift detector energy-dispersive X-ray spectrometry (SEM/SDD-EDS)," Journal of Materials Science, vol. 50, no. 2, pp. 493-518, 2014.

[24] C. T. Kresge, M. E. Leonowicz, W. J. Roth, J. C. Vartuli, and J. S. Beck, "Ordered mesoporous molecular sieves synthesized by a liquid-crystal template mechanism," Nature, vol. 359, no. 6397, pp. 710-712, 1992.

[25] S. H. Chai, H. P. Wang, Y. Liang, and B. Q. Xu, "Sustainable production of acrolein: gas-phase dehydration of glycerol over 12tungstophosphoric acid supported on $\mathrm{ZrO} 2$ and $\mathrm{SiO} 2$, , Green Chemistry, vol. 10, no. 10, pp. 1087-1093, 2008.

[26] S. J. Gharpure and S. K. Nanda, "Stereoselective synthesis of thiazino[4,3-: A] indoles using the thia-Pictet-Spengler reaction of indoles bearing $\mathrm{N}$-tethered thiols and vinylogous thiocarbonates," Organic \& Biomolecular Chemistry, vol. 14, no. 24, pp. 5586-5590, 2016. 

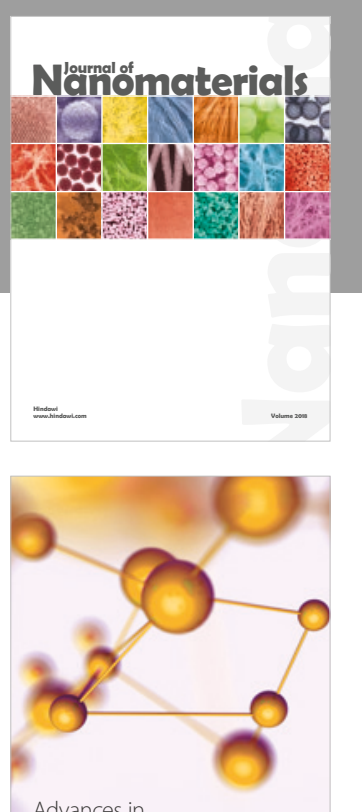

Physical Chemistry
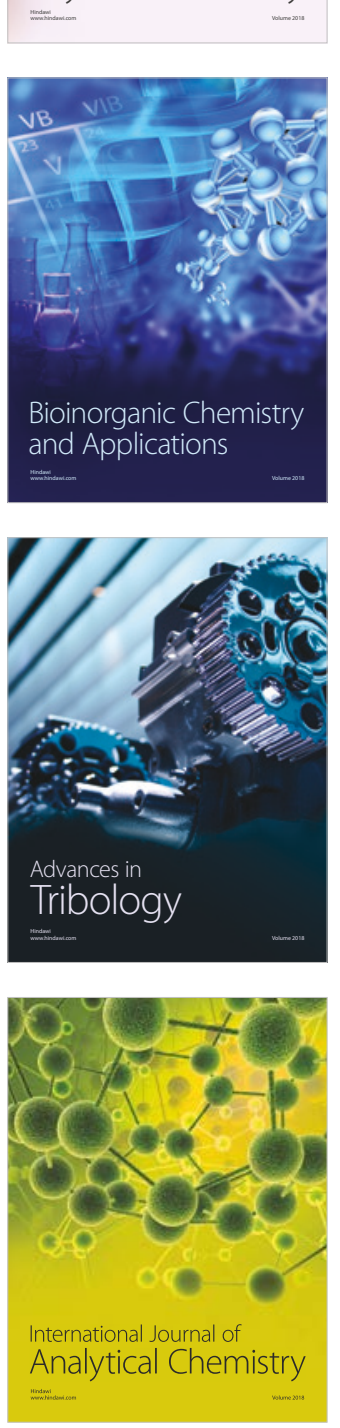

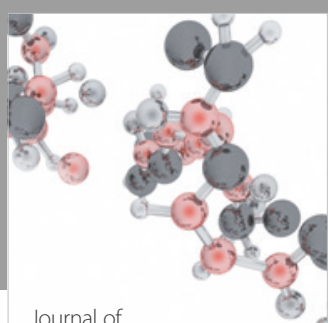

Analytical Methods

in Chemistry

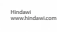

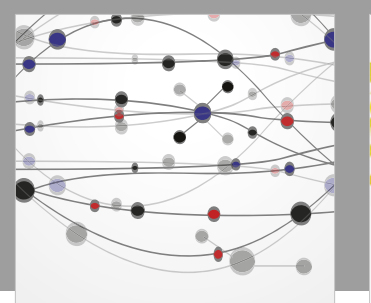

The Scientific World Journal

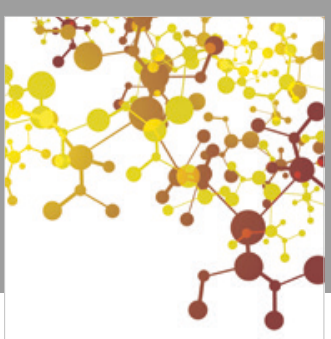

Journal of

Applied Chemistry
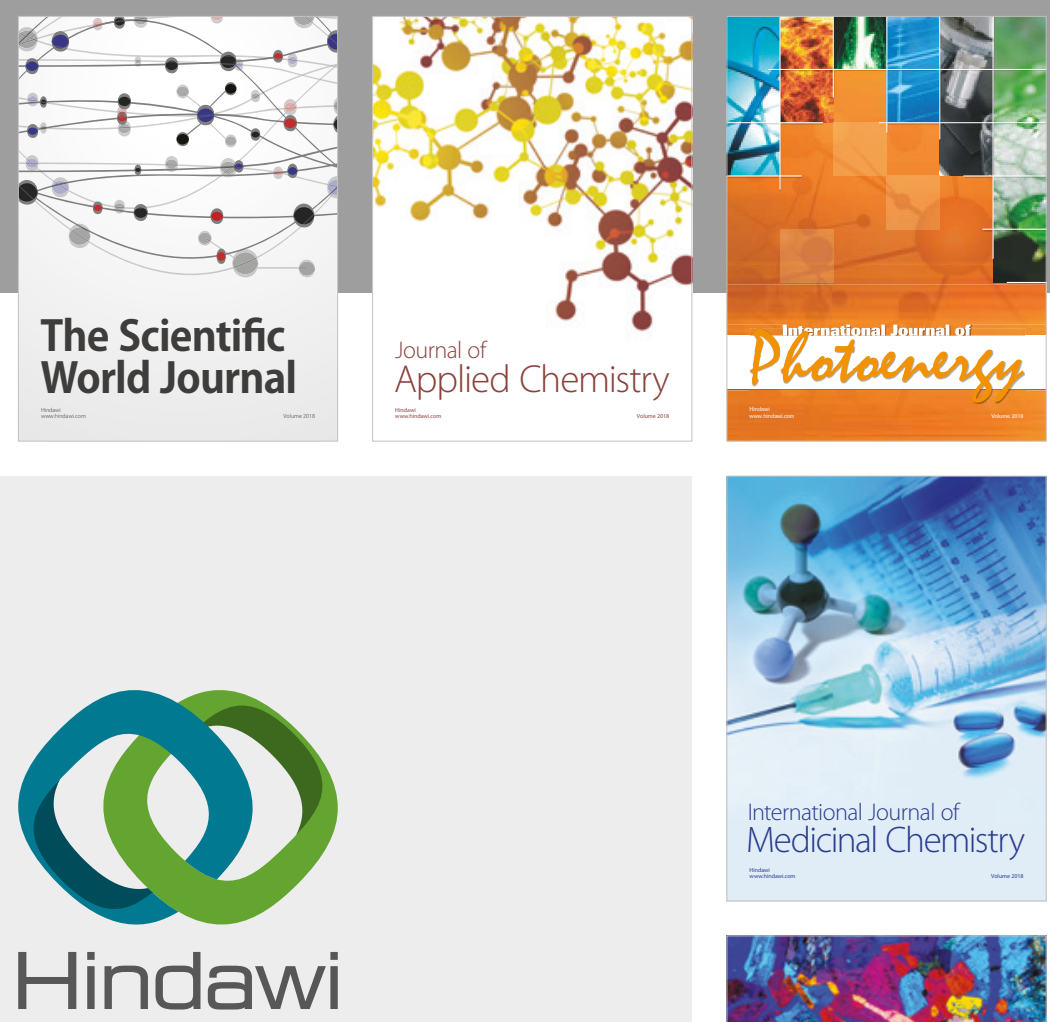

Submit your manuscripts at

www.hindawi.com
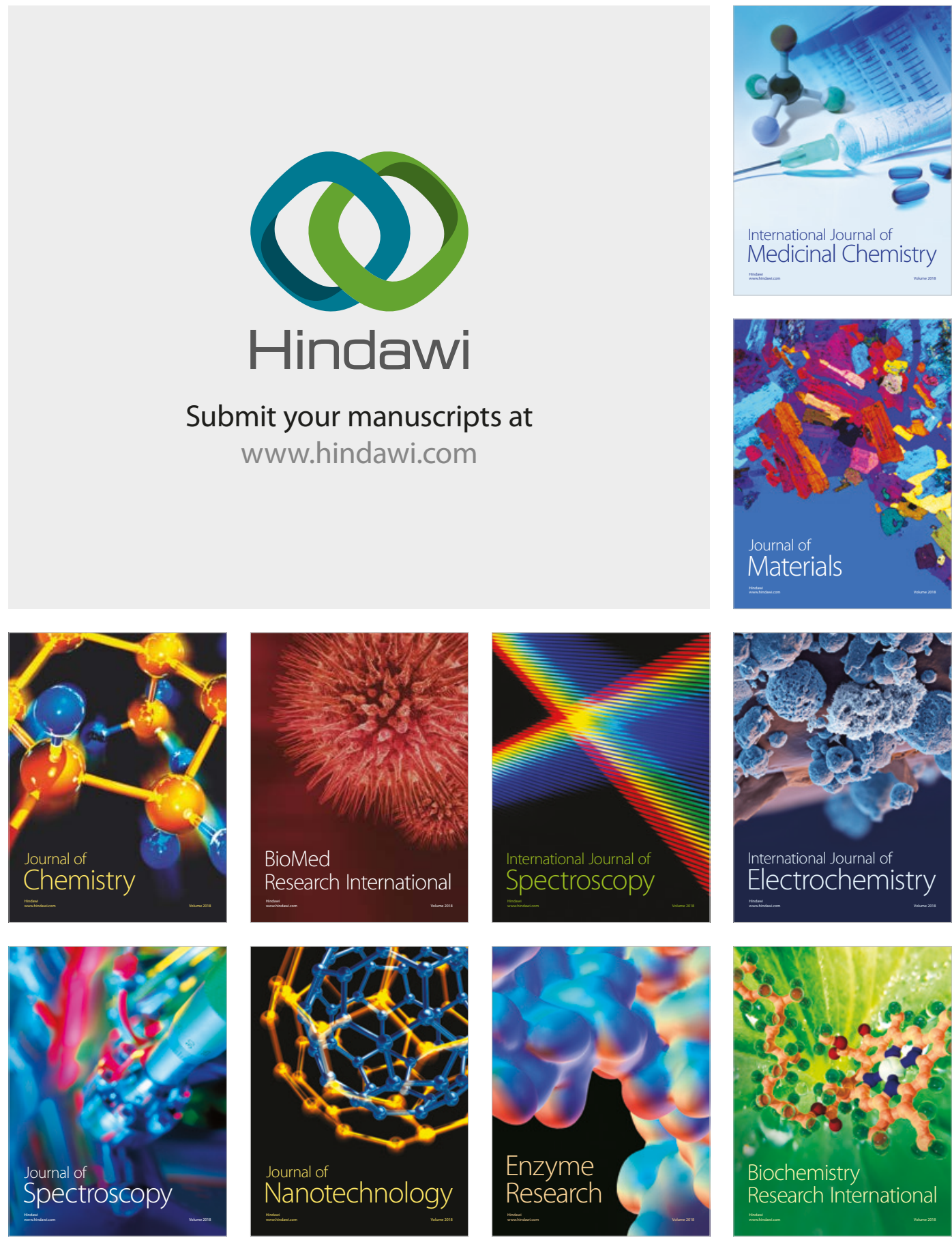
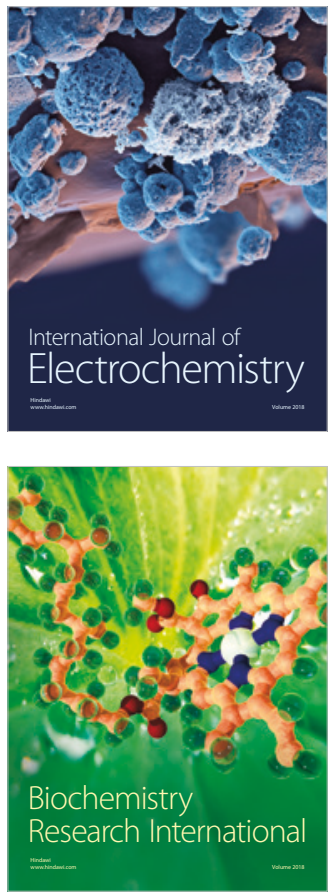